\title{
Review of Progress on VDatum, a Vertical Datum Transformation Tool
}

\author{
Edward P. Myers \\ NOAA/NOS Coast Survey Development Laboratory, Silver Spring, Maryland
}

\begin{abstract}
VDatum is a software tool developed by the National Ocean Service that allows users to transform geospatial data among a variety of geoidal, ellipsoidal, and tidal vertical datums. This is important to coastal applications that rely on vertical accuracy in bathymetric, topographic, and coastline data sets. The VDatum software can be applied to a single point location or to a batch data file. Applying VDatum to an entire data set can be particularly useful when merging multiple data sources together, where they must first all be referenced to a common vertical datum. Emerging technologies, such as lidar and kinematic GPS data collection, can also benefit from VDatum in providing new approaches for efficiently processing shoreline and bathymetric data with accurate vertical referencing. Given the numerous applications that can benefit from having a vertical datum transformation tool, the goal is to develop a seamless nationwide VDatum utility that would facilitate more effective sharing of vertical data and also complement a vision of linking such data through national databases.
\end{abstract}

\section{INTRODUCTION}

Many applications are dependent upon accurate bathymetry and topography, and sources of these data can be quite diverse. For example, bathymetry is usually referenced to a tidal datum, lidar data may be referenced to an ellipsoidal datum, and topographic data may be tied to an orthometric datum. A typical user of each data set is often confronted first with the question of how to reference the data to a different vertical datum. Without a vertical datum transformation tool, discontinuities will occur at the intersections of data sets that are referenced to different datums.

Coastline data referenced to different datums involve horizontal shifts as well as changes in shape. A shoreline representing the mean high water (MHW) line, for example, looks very different than the zero contour of an orthometric datum. This is likewise true for all marine boundaries used to demarcate international, federal, and state maritime limits.

As coastal data becomes more abundant with improved observation technology, there is an imperative need to manage such data properly. Coalescing multiple data sets into uniform products is only meaningful when the elevation (height or depth) data are referenced to a common vertical datum [1]. Without a vertical datum transformation tool, the utility of the data is often compromised, particularly in nearshore coastal areas.

The National Oceanic and Atmospheric Administration (NOAA) and the U.S. Geological Survey (USGS) first addressed the vertical datum transformation issue by collaborating on the pilot project of VDatum in the Tampa Bay region [2]. The VDatum software was designed to accomodate 28 transformations spanning the three major classes of vertical datums : orthometric, ellipsoidal, and tidal. A geoid model was used to convert between orthometric and ellipsoidal datums, a topography of the sea surface was computed to relate orthometric and tidal datums, and tidal modeling was used to compute the tidal datums. The output from each of these models was integrated into the VDatum software and then applied to bathymetry and topography for Tampa Bay. Hydrographic survey data from NOAA, topographic data from the USGS, and other third-party elevation data were all converted to a common vertical datum using the VDatum software. These data were then integrated into a digital elevation model (DEM) to form a seamless data set across the landwater interface.

The successful development and implementation of VDatum in Tampa Bay showed how data could be made more useful to coastal managers and applications. Not only were all existing bathy/topo data integrated into a seamless DEM, but the tool can also be used to transform all future elevation data acquired in the area. Shorelines may be more accurately computed by applying VDatum to lidar data. Bathymetry may be more easily referenced to a vertical datum, without installation of temporary tide gauges concurrent to hydrographic survey operations. Furthermore, applications dependent on a seamless landwater DEM are now more accurate, including storm surge modeling, habitat restoration, sea level rise effects, and ecosystem studies. All of the benefits of having VDatum available in an area such as Tampa Bay demonstrated its potential utility in serving as a national backbone for linking and transforming elevation data from a multitude of sources.

Building a national VDatum [3] has since proceeded with applications to the New York Bight [4], central California [5], southeast Louisiana, Delaware Bay [6], and Puget Sound [7]. VDatum is also in development for North Carolina, Louisiana's Calcasieu River and Lake Charles [8], the Chesapeake Bay, New York Harbor/Long Island Sound, the Gulf of Maine, Strait of Juan de Fuca, and Southern California. As the regional VDatum applications begin to overlap, a seamless VDatum software will emerge to cover all of the U.S. coastal areas out to 25 nautical miles from land. The availability of VDatum nationwide will enable bathymetric, topographic and coastline data to be easily transformed and assembled in a manner that complements dissemination through national databases.

NOAA's National Ocean Service (NOS) has developed an approach for expanding VDatum that streamlines techniques and resources. Much of the time spent in developing VDatum for a new area is in the setup and calibration of the hydrodynamic model used to simulate the tides. Standardized approaches for assembling input data used by the models, generating the model grids, and running numerical tide simulations have been adopted to efficiently compute the tide datums. Once these tidal datums are combined with geoidal and sea surface topography results for a given area, the VDatum transformations are made available both as a standalone software utility and through a web interface. 


\section{VDATUM TRANSFORMATIONS AND SOFTWARE}

\section{A. Vertical Datum Transformations}

The VDatum pilot project in Tampa Bay was designed to address the issue of discontinuities in vertical datums between the topographic products distributed by the USGS and the bathymetric products of NOAA. The USGS products are generally referenced to an orthometric datum, such as the North American Vertical Datum of 1988 (NAVD88) or the older National Geodetic Vertical Datum of 1929 (NGVD29). NOAA bathymetry, on the other hand, is tied to tidal datums such as mean lower low water (MLLW) or mean low water (MLW). Many coastal applications, though, depend on the need to accurately depict the transition between land and water. In addition, the coastline as defined relative to one vertical datum can look very different from that defined to another, thus leading to more confusion on the part of users requiring coastal boundary information.

In addition to bathymetric/topographic data provided by NOAA and the USGS, there are many other sources of height data. For example, lidar data provides high resolution data in the nearshore environment, both for topographic elevations and for shallow water bathymetry (dependent on water clarity, since high turbidity can limit the return signal). This data provides an excellent link between NOAA's bathymetric soundings and USGS topography. Lidar uses a global positioning system (GPS) to compute elevations relative to an ellipsoid. Therefore, VDatum has transformations to accomodate ellipsoidally referenced data.

In all, there are 28 vertical datums embedded within VDatum between which the user can transform height data. There is also a horizontal datum conversion available to map between the North American Datum of 1983 (NAD83) and the North American Datum of 1927 (NAD27). The suite of vertical datums was designed to be extensive in anticipation of the multiple possibilities that coastal applications may require.

The vertical datums available in VDatum are shown in Fig. 1. The datums here are categorized as ellipsoidal, orthometric, and tidal. Transformations within each vertical datum group are made using slightly different approaches. Among ellipsoidal datums, 7-parameter Helmert transformations are implemented within the VDatum software. There are only two orthometric datums, NAVD88 and NGVD29, and the VERTCON algorithms developed by NOAA's National Geodetic Survey are used to compute differences between them. For the tidal datums, hydrodynamic models are used to compute mean higher high water (MHHW), MHW, mean sea level (MSL), mean tide level (MTL), diurnal tide level (DTL), MLW and MLLW. These tidal datums are provided as a set of regularly gridded points, from which the Vdatum software will interpolate to a user-defined set of points.

Within each of the three groups of vertical datums, there is a primary datum, shown in bold in Table I. Transformations that occur between categories are made between these primary datums. For example, to transform MLLW data to WGS 84, the transformations will occur in the following order: 1) MLLW to MSL, 2) MSL to NAVD88, 3) NAVD88 to NAD83 (86), and 4) NAD83(86) to WGS 84. There are two transformations used by VDatum to convert between the three datum categories.

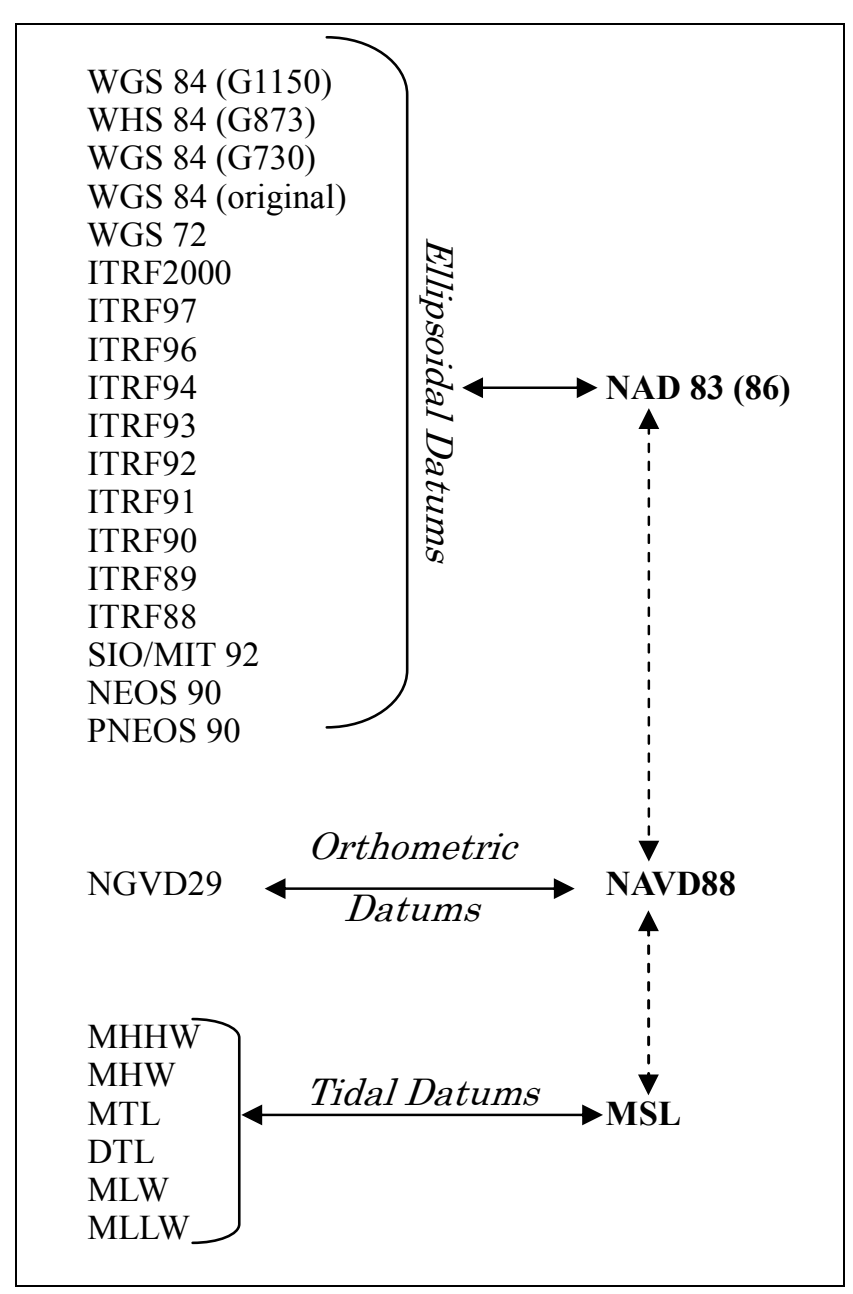

Fig. 1. Vertical Datum Transformations in VDatum.

The first is a computed topography of the sea surface (TSS), and this is used to interpolate differences between MSL and NAVD88. Observed MSL-NAVD88 differences from benchmarked tide stations are spatially interpolated using techniques such as Kriging to obtain a regularly gridded set of points. VDatum uses this grid to interpolate the differences at the points provided by the user. The second VDatum transformation between datum categories is between NAVD88 and NAD83 (86), and the geoid model GEOID99 $[9,10]$ is used to compute these geoidellipsoid differences. VDatum uses a gridded set of these differences for interpolation at the user-defined input locations.

\section{B. VDatum Software}

The VDatum software can be accessed via the web, at http://nauticalcharts.noaa.gov/csdl/vdatum.htm. Only those areas where it has been developed are available. The Java based application can be downloaded onto the user's computer for the area of interest. The user then has the option of inputting either a single point location or a file of points for batch processing. The software is currently being integrated into an interactive web interface. While this will allow the user to not have to download the software, the resulting computations are slower due to exchange of information between servers used to process user requests. The resulting web interface will also be designed so that the user does not have to choose which 
VDatum area is to be used. After inputting a set of points, the interface will return the transformation along with information on which VDatum applications were used to compute the transformation.

Fig. 2 shows the VDatum software interface that appears in both the downloadable software as well as in the web interface formats. The top image shows the interface for a single point conversion, and the bottom shows the batch file conversion utility.

\section{PRODUCTS DERIVED FROM VDATUM}

\section{A. Digital Elevation Models}

Once VDatum is available for a given region, it enables multiple datasets to be referenced to a common vertical datum and then combined. These combined datasets can then be formatted into a quality-controlled, gridded digital elevation model. High resolution DEMs, particularly those that include both topography and bathymetry, are an invaluable resource to coastal and scientific applications.

The pilot project of VDatum in Tampa Bay facilitated the building of a DEM using NOAA hydrographic survey data and USGS topographic data. Bathymetry from NOAA's GEODAS database were filtered according to survey dates, giving the more recent surveys higher priority when assembling the DEM. The vertical datums of these data were a mix of MLW and MLLW, all of which was converted to NAD83 through VDatum. Elevation data from the USGS National Elevation Dataset (NED) were quality-controlled at a 1-arc-second horizontal resolution, and the vertical datums were converted from NAVD88 to NAD83 using VDatum transformations. Using the NED shoreline as the dividing line between land and water, the resulting bathymetric and topographic points were assembled in a 1 -arc-second mosaic DEM using a spline interpolation technique. An image of the Tampa Bay DEM is displayed in Fig. 3.

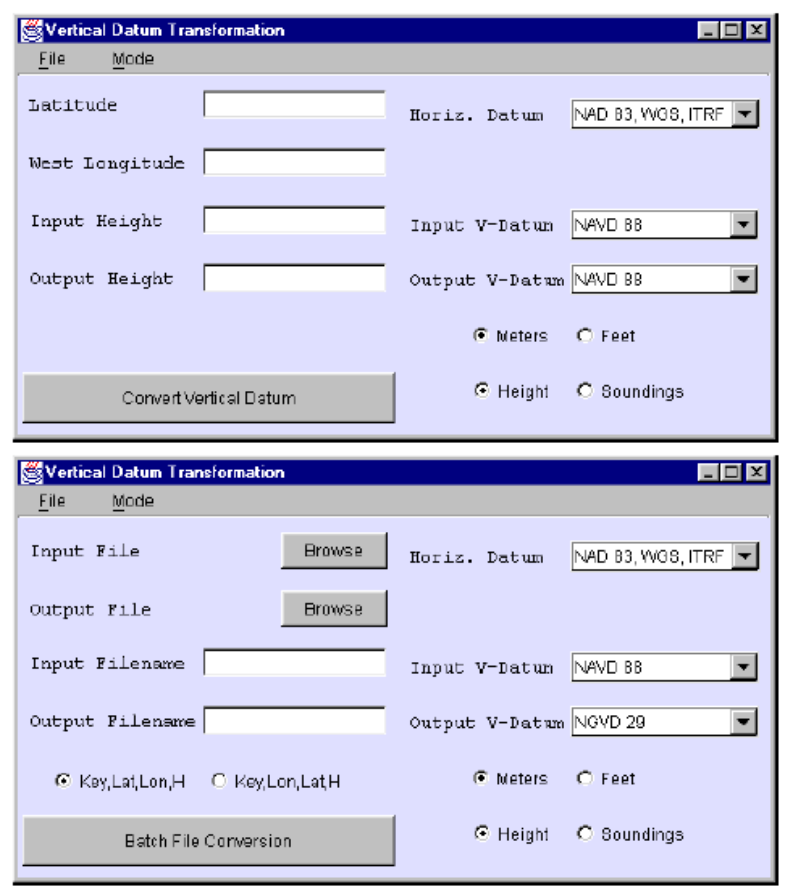

Fig. 2. VDatum software interface.

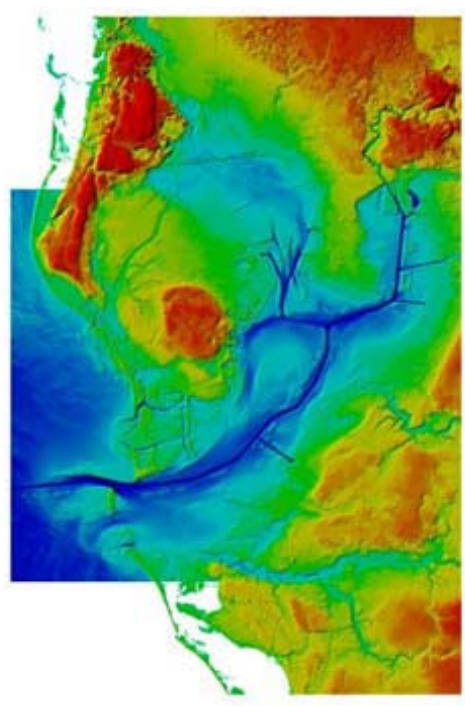

Fig. 3. DEM created for Tampa Bay using VDatum conversions.

The VDatum application more recently developed for North Carolina was also used to generate a high resolution DEM referenced to NAVD88. Bathymetric data from both NOAA and the U.S. Army Corps of Engineers was used as input for the water depths, while topographic heights were extracted from the USGS NED and lidar data derived from the Federal Emergency Management Agency (FEMA). The lidar data are available in raw point format, as bareearth points, and regular gridded data. The bare-earth data represent the true ground surface, as the original data set was filtered to remove vegetation, buildings, and other obstructions. The bare-earth data was primarily used in the construction of the topographic portion of the DEM. In areas not covered by lidar data, the USGS NED was used.

The resulting North Carolina DEM has a horizontal resolution of approximately 6 meters. The vertical accuracy is about $20 \mathrm{~cm}$ in coastal counties and around $25 \mathrm{~cm}$ in inland regions. A segment of this DEM is shown in Fig. 4.

DEMs such as those prepared for Tampa Bay and North Carolina using VDatum provide a valuable resource in linking data from multiple sources. VDatum thus enables the production of seamless DEMs across the land-water interface. As VDatum expands to national coverage, these bathy/topo DEMs will likewise become a seamless product available throughout the nation's coastal regions.

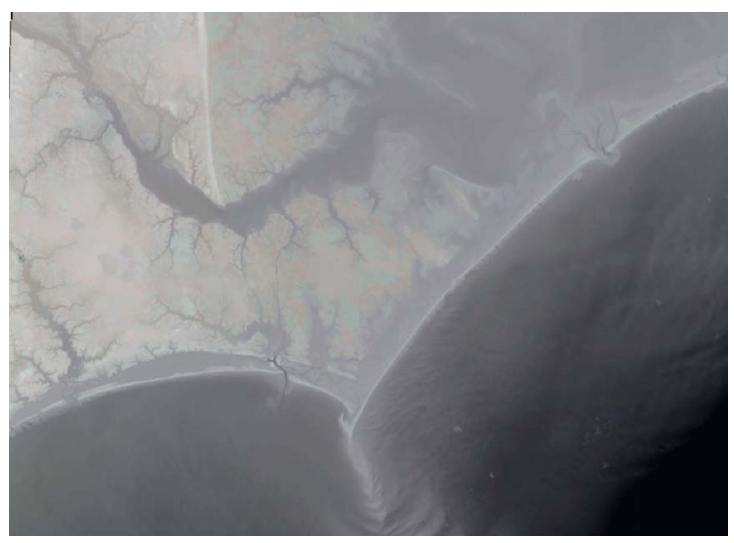

Fig. 4. Segment of the North Carolina DEM. 


\section{B. National Bathymetric Database}

A national VDatum will also facilitate improved organization and dissemination of bathymetric data sets maintained by NOAA. Current NOAA bathymetry is often made available relative to the local tidal datum of interest, most often either MLLW or MLW. Linkage between processing of bathymetric datasets and a national VDatum would therefore allow users to access a national bathymetric database for which depths could be extracted relative to the vertical datum of interest.

NOS is developing a national database to house data from historical hydrographic surveys, multibeam surveys, local spot soundings, lidar measurements, USACE dredging areas, and other data sources. VDatum will be used to transform all data to a common vertical datum, from which integrated bathymetric products can be produced. Products that could be delivered through this database include a Navigation Surface $[11,12]$ and standard bathymetric interpolation algorithms. A diagram of the NOS bathymetric database strategy is shown in Fig. 5.

\section{Coastlines and Marine Boundaries}

In coastal regions, the land-water interface is dependent on how water levels change in both space and time. This is likewise true for many marine boundaries that are defined as a certain distance from the shoreline. The legal shoreline as defined on NOAA nautical charts is the MHW line. States also set boundaries at either the MHW, MHHW, or MLLW line to separate state and privately owned lands. Such state, federal and international marine boundaries and coastlines are all therefore referenced relative to a vertical datum, as shown in Fig. 6.

However, how does one compute a boundary that is tied to a vertical tidal datum such as MHW? Shorelines are often computed from aerial photographs, ideally taken near the time when the water levels are close to the reference datum. But this is difficult, for several reasons [13]. First (taking MHW as an example) MHW is a computed value taken as an average height of high waters over a long period of time. Therefore, flying a survey near high water on a given day will not necessarily be the same as flying at the time that water levels are at MHW. Second, MHW will vary both spatially and temporally. High tides will not occur at the same time in all the regions covered by an aerial survey. Finally, there may be other factors affecting the water level during a survey, including wind (both nearfield and far-field) and density (salinity, temperature)

\section{NOAA NOS Bathymetric Database}

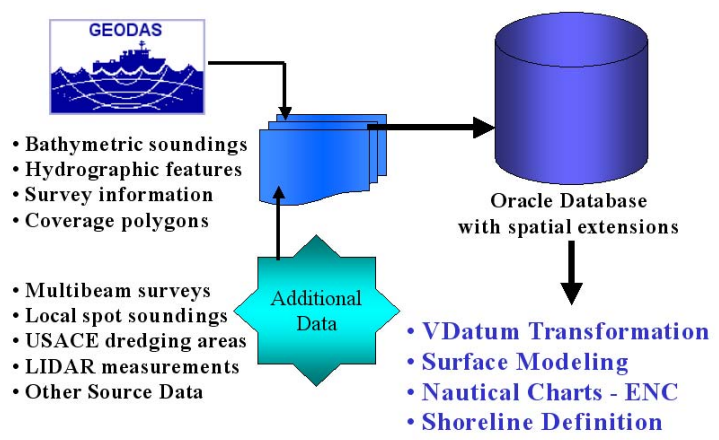

Fig. 5. Structure of the NOS bathymetric database in development.

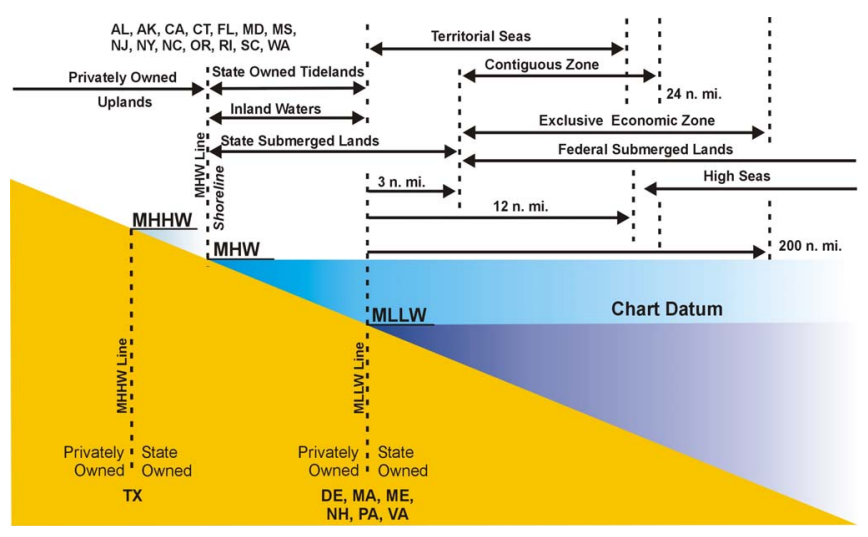

Fig. 6. Shoreline and marine boundaries defined relative to tidal datums.

related effects. Given these limitations, though, agencies need to be consistent in their definitions of boundaries and do their best to minimize the errors involved in the process.

VDatum offers an alternative to computing boundaries from aerial photography. High resolution lidar data can be used in conjunction with VDatum to accurately compute shorelines referenced to tidal datums [14]. Lidar data referenced to an ellipsoidal datum can simply be filtered through VDatum to reference the data to MHW. The zero height contour of this dataset will thus represent the MHW shoreline boundary. If topographic lidar data are used, the data needs be acquired at a time when the water levels in the area are below the tidal datum of interest (MHW, for example). Fig. 7 shows an example of deriving MHW from VDatum-corrected lidar data (green line) as contrasted with the shoreline displayed on NOAA T-sheets (red line). Similarly, water-penetrating lidar systems such as SHOALS (Scanning Hydrographic Operational Airborne Laser Survey) and LADS (Laser Airborne Depth Sounder) can be flown when water levels are above a datum such as MLLW. The resulting depths can similarly be transformed from an ellipsoidal reference to MLLW, and the zero contour of this new dataset will represent the MLLW shoreline. As VDatum expands, a national shoreline derived from VDatum transformations applied to lidar could replace existing shoreline databases.

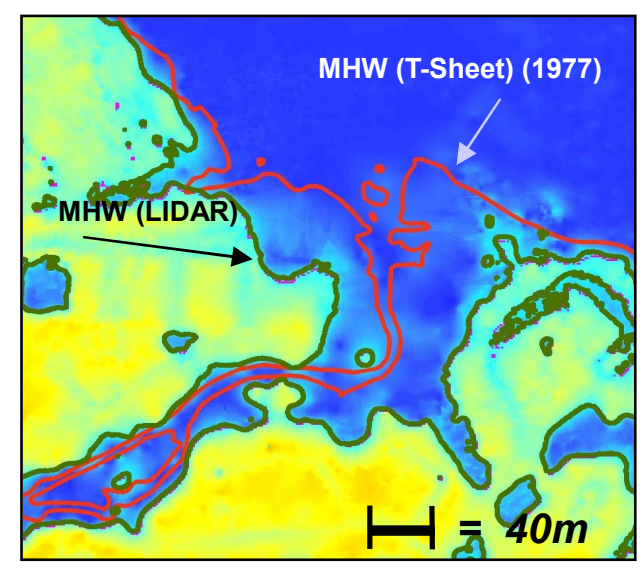

Fig. 7. MHW computed using VDatum-corrected lidar data as compared to MHW as displayed on the NOAA T-Sheet from 1977. 


\section{APPLICATIONS USING VDATUM PRODUCTS}

\section{A. Kinematic GPS (KGPS) Hydrographic Surveys}

While VDatum is useful in transforming existing bathymetric data, it is envisioned as becoming a vital part in the processing of KGPS hydrographic survey data for nautical charting. The echosounding equipment on a survey vessel are located at a known distance from the onboard KGPS reference point. Therefore, all depths are measured relative to an ellipsoid, thus eliminating the need for any settlement or squat corrections [15]. The KGPS data include the tidal responses on the hydrogaphic survey vessel. By using KGPS methods in areas where VDatum is available, the need to install temporary tide gauges concurrent to hydrographic survey operations may be eliminated. Ellipsoidal bathymetry may be more precisely and efficiently processed, and VDatum may be used to accurately reference these data to the NOAA chart datum of MLLW.

\section{B. Hydrodynamic Modeling Applications}

Hydrodynamic models applied to ocean, coastal, and estuarine regions are used to compute water level, current, salinity and temperature fields that vary in both space and time. These models also simulate inundation and are therefore used to evaluate flooding impacts from events such as storm surge and tsunamis. Forecast models that simulate the daily flows in coasts and estuaries are also increasingly including inundation and drying of low elevation areas such as intertidal flats.

Model simulations of inundation require high resolution numerical grids that extend from the water onto the land as far as the inundation is expected to propagate. The grids, whether they are structured (finite difference grids) or unstructured (e.g. triangular grids), must therefore contain accurate bathy/topo data at each discrete grid point. If there are discontinuities between the land elevations and water depths caused by disregard for matching vertical datums in the original bathy/topo datasets, these will adversely affect the models' ability to accurately represent the inundation.

High resolution DEMs that have been assembled using VDatum transformations are therefore ideal as input to numerical models that simulate inundation. The heights from the DEM are interpolated onto the hydrodynamic model grid points. Ideally, the horizontal resolution in both the DEM and the model grid should be refined enough so as to accurately depict the scale of geographic changes in the bathy/topo landscape.

As an example, the DEM developed for North Carolina using VDatum transformations is being used to study coastal hydrodynamic changes due to sea level rise [16]. A numerical model is being developed to simulate how inundation from tidal propagation, wind-driven circulation, and storm surge events might change in the nearshore environment given a specified offshore eustatic sea level rise. An unstructured triangular grid has been constructed with bathy/topo data interpolated from the DEM, and this grid will be used to perform numerical simulations using the finite element model ADCIRC [17]. The model grid, shown in Fig. 8, extends landward to a 15 meter topographic height. The use of an unstructured triangular grid allows more refinement to be placed in the nearshore environment, particularly transitioning from water to land.

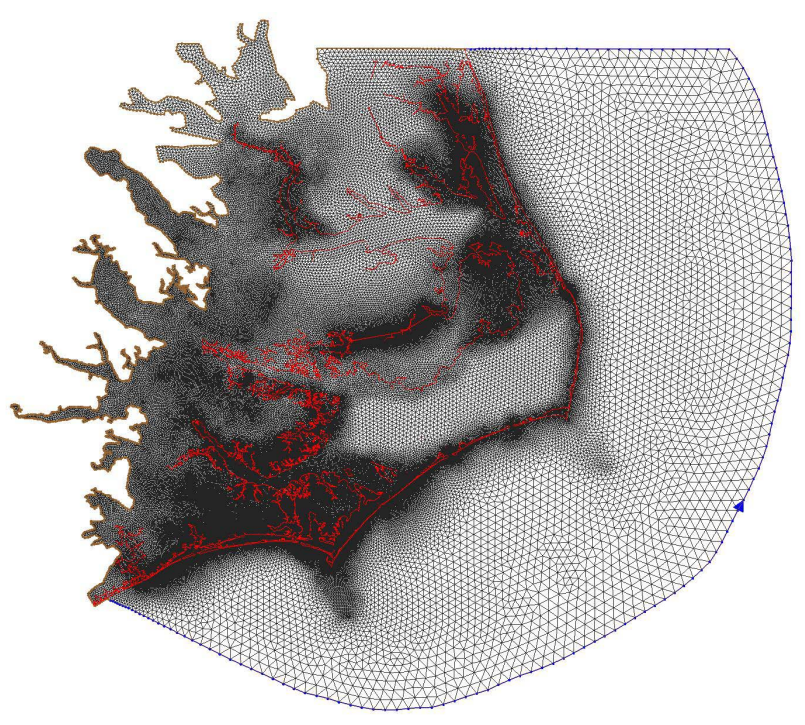

Fig. 8. North Carolina coastal flooding model grid with NOAA MHW shoreline in red.

Results from the North Carolina coastal flooding model will also be used to compute shorelines under the sea level rise scenarios considered. Tidal datums such as MHW and MLLW will be computed from simulations imposing a combination of tides and sea level rise, and the resulting datum surfaces will be analyzed for where they intersect the DEM. This intersection will represent the new shoreline as defined relative to the given tidal datum. Fig. 9 shows an example of changes in MHW from present-day sea level (dark blue line) to a sea level rise of $30 \mathrm{~cm}$ (light blue line), using preliminary model results near Morehead City, NC. These computed shorelines are overlaid on the NOAA chart which shows the MHW shoreline as the solid black line.

\section{Coastal Ecosystem Response to Sea Level Rise}

Evaluating the impacts of sea level rise in nearshore environments is strongly dependent on the accuracy of data defining the land-water transition zone. A high resolution, VDatum-adjusted continuous DEM, therefore, is

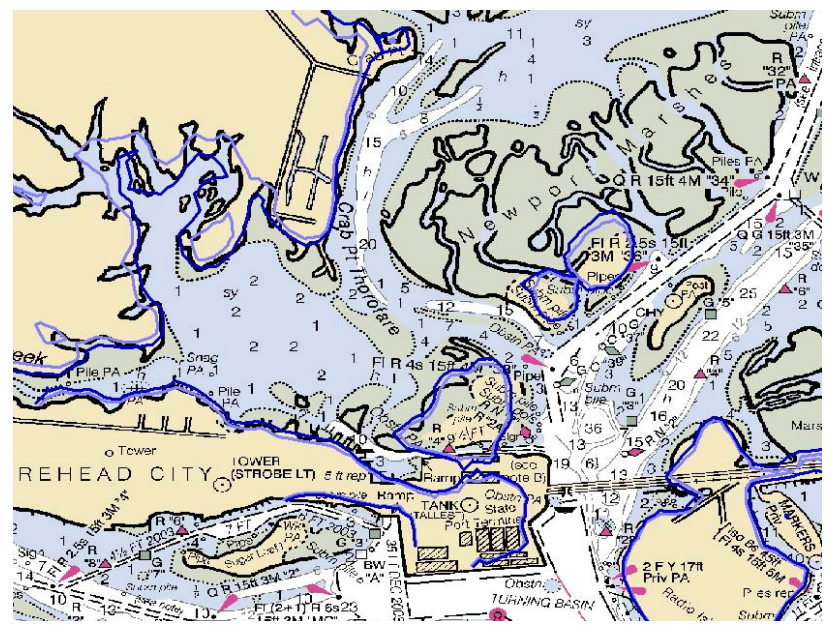

Fig. 9. Sea level rise effects on MHW shoreline using prelimninary

hydrodynamic model results. Current MHW is shown as the dark blue line, and MHW given a $30 \mathrm{~cm}$ sea level rise is shown as the light blue line. 
invaluable in this respect. The North Carolina DEM was shown to be useful for developing hydrodynamic models to evaluate sea level rise effects, and these simulations in turn are being coupled to ecological submodels. For example, models that simulate salt marsh accretion will be linked to the hydrodynamic model results to evaluate tidal marsh response to sea level rise.

\section{FUTURE DIRECTION FOR VDATUM}

There is a close synergy between all of the products, applications and technologies presented here that would not be possible if not for VDatum acting as the catalyst. It is therefore a high priority to continue to expand VDatum until nationwide coverage is achieved. The ability to effectively link data will ultimately enable coastal managers, scientists, and communities to more easily work with data describing the coastal landscape.

NOS is working on improving the efficiency by which VDatum applications may be developed. As much of the work involved in creating an application is devoted to the tide modeling, standardized approaches have been devoted to this component of VDatum. Each of these steps in preparing and calibrating the model simulations reduces the amount of time it takes to develop a VDatum application. Generating the model grids has been standardized, so that common approaches and input data are used to create the unstructured triangular grids. The pre- and post-processing routines for analyzing model simulations have also been standardized among project applications.

The grids being used by current VDatum tide modeling applications contain a large number of discrete points, due in large part to the increased resolution in nearshore coastal regions. The simulations on these grids are therefore computationally intensive and can normally take several months to run on a single processor computer. Hence, the simulations are being made in parallel on NOAA's Forecast Systems Laboratory (FSL) cluster computing environment. Running the ADCIRC model as a parallel code on FSL's computers allows the simulations to be made in about one day.

Furthermore, as these high resolution tide modeling grids are developed for VDatum, they are also serving to address other hydrodynamic modeling applications. For example, storm surge simulations are being made on either the same grids or slightly adjusted versions of those grids. The grids will also be made available to nowcast/forecast modeling efforts within NOAA [18].

Fig. 10 shows examples of the grids generated for VDatum applications in New York and North Carolina. Along the open ocean boundary of each, tides are imposed as boundary conditions from a larger scale regional model. An example of such a regional model is the EastCoast2001 database [19], which was derived from ADCIRC simulations on the grid shown in Fig. 11. As the regional VDatum tide modeling applications begin to overlap to form continuous coverage of the nation's coastline, the resulting database of unstructured grids can similarly be blended together into a single high resolution regional grid on which hydrodynamic simulations may be carried out.

Several national databases have been mentioned here, including the ones for unstrucutred grids, bathymetry/topography, and coastlines. All of these

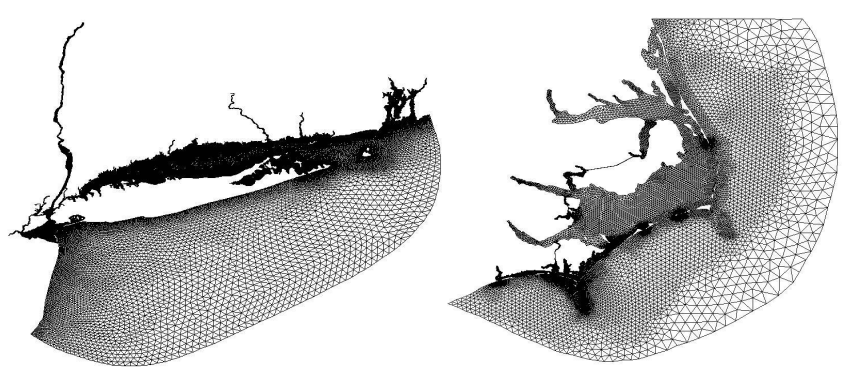

Fig. 10. VDatum tide model grids for New York and North Carolina

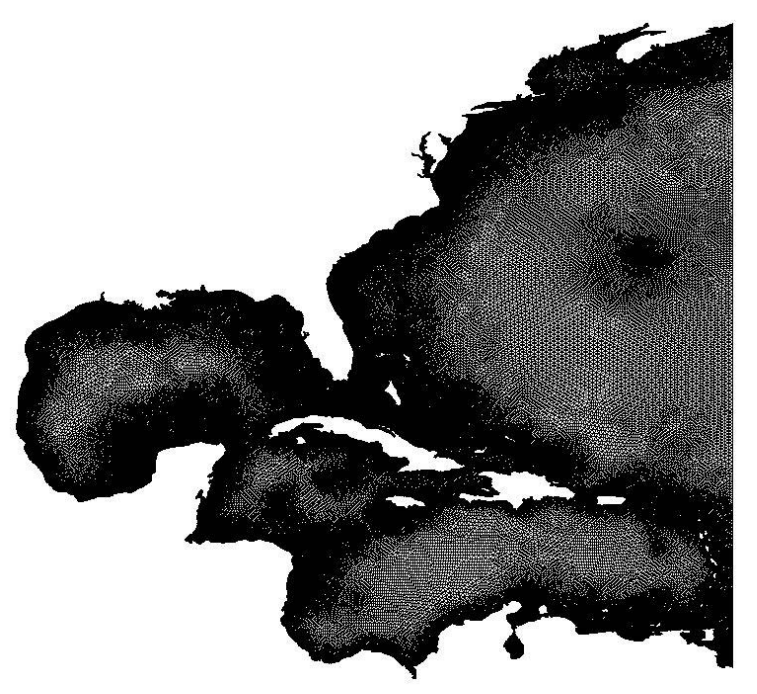

Fig. 11. EastCoast2001 regional tide model grid.

contribute to easier access to coastal data made more accurate through appropriate vertical transformations. To improve dissemination of such databases, the VDatum webpage is being evaluated for how it may best meet the needs of its users. As mentioned, a web interface of the VDatum software is in development, and GIS formatted products are also being generated for possible delivery via the web. With better access to VDatum and national databases, coastal applications will have greater confidence in the accuracy and consistency of the data representing the coastal zone transition between water and land.

\section{Acknowledgments}

Development of VDatum has been a team effort that is the culmination of collaborative efforts of many personnel from the Coast Survey Development Laboratory (CSDL), National Geodetic Survey (NGS), and the Center for Operational Oceanographic Products and Services (COOPS), all part of NOAA's National Ocean Service. The vision for a national VDatum was led by Bruce Parker (CSDL), Dennis Milbert (NGS), Kurt Hess (CSDL) and Stephen Gill (CO-OPS). VDatum applications have been funded from a variety of sources, including NOS' National Centers for Coastal Ocean Science, NOAA's National Marine Sanctuary Program, the United States Geological Survey, and the Army Corps of Engineers. NOAA's Forecast Systems Laboratory allows the use of their cluster computing environment in running parallel tide simulations in support of VDatum. 


\section{REFERENCES}

[1] National Research Council, A Geospatial Framework for the Coastal Zone, The National Academies Press, Washington, D.C., 149 p., 2004.

[2] D.G. Milbert and K.W. Hess, "Combination of topography and bathymetry through application of calibrated vertical datum transformations in the Tampa Bay region", Proceedings of the Second Biennial Coastal GeoTools Conference, Charleston, South Carolina, 8 - 11 January 2001.

[3] B. Parker, K.W. Hess, D.G. Milbert, and S. Gill, "A national vertical datum transformation tool", Sea Technology, Volume 44, Number 9, pp. 10-15, September, 2003.

[4] K.W. Hess, Generation of tidal datum fields for Tampa Bay and the New York Bight, U.S. Department of Commerce, National Oceanic and Atmospheric Administration, Silver Spring, Maryland, NOAA Technical Report NOS CS 11, 43 p., 2001.

[5] E.P. Myers, Modeling of tidal datum fields in support of VDatum development along the North and Central coasts of California, unpublished.

[6] B. Parker, K.W. Hess, D.G. Milbert, and S. Gill, "Vertical datum transformations for kinematic GPS hydrographic surveys, U.S. Hydrographic Conference, Biloxi, Mississppi, 2003.

[7] K.W. Hess and S.A. White, VDatum for Puget Sound: generation of the grid and population with tidal datums and sea surface topography, U.S. Department of Commerce, National Oceanic and Atmospheric Administration, Silver Spring, Maryland, NOAA Technical Memorandum NOS CS 4, 27 p., 2004.

[8] E.A. Spargo and J.W. Woolard, VDatum for the Calcaseiu River from Lake Charles to the Gulf of Mexico, Louisiana: tidal datum modeling and population of the grid, U.S. Department of Commerce, National Oceanic and Atmospheric Administration, Silver Spring, Maryland, NOAA Technical Memorandum NOS CS 19, 26 p., 2005.

[9] D.A. Smith and D.R. Roman, "Recent advances in the acquisition and use of terrain data for geoid modelling over the United States", presented at $I A G$ Session $G 3 / W$ of the IUGG meeting in Birmingham, England from July 18 - 30, 1999.

[10]D.A. Smith and D. R. Roman, "GEOID99 and G99SSS: one arc-minute models for the United States", J. Geodesy, vol. 75, pp. 469-490, 2001.

[11]S.M. Smith, The Navigation Surface: A Mutlipurpose Bathymetric Database, Master's thesis, Center for Coastal and Ocean Mapping and National Oceanic and Atmospheric Administration / University of New Hampshire Joint Hydrographic Center, 2003.

[12]Smith, S. M., L. Alexander, and A.A. Armstrong, "The Navigation Surface: a new database approach to creating multiple products from high density surveys", International Hydrographic Review, 3(2):12-26, 2002.

[13]B. Parker, "Where is the shoreline?", Hydro International, 6-9, 2001.

[14]B. Parker, "The difficulties in measuring a consistenly defined shoreline - the problem of vertical referencing", Journal of Coastal Research, 38, 44-56, 2003.

[15]B. Parker, "The integration of bathymetry, topography and shoreline and the vertical datum transformations behind it", International Hydrographic Review, 3(3), 35-47, 2002.

[16]K.W. Hess, S.A. White, J. Sellars, E. Spargo, A. Wong, S.K. Gill, and C. Zervas, North Carolina sea level rise project: interim technical report, NOAA Technical Memorandum NOS CS 5, NOAA, 26 p., 2004.

[17]R.A. Luettich, J.J. Westerink, and N.W. Scheffner, ADCIRC: an advanced three-dimensional circulation model of shelves, coasts and estuaries, Report 1: theory and methodology of ADCIRC-2DD1 and $A D C I R C-3 D L$, Technical Report DRP-92-6, Department of the Army, Vicksburg, MS, 1992.

[18]F. Aikman, T. Gross, and M. Vincent, "Operational estuarine and coastal forecast hydrodynamic modeling and development in the National Ocean Service", 8th International Estuarine and Coastal Modeling Conference, 2003.

[19]A. Mukai, J.J. Westerink, R.A. Luettich and D. Mark, A tidal constituent database for the Western North Atlantic Ocean, Gulf of Mexico and Caribbean Sea, Technical Report, U.S. Army Engineer Research and Development Center, Vicksburg, MS, September 2001. 